\title{
Impact of Hemodialysis on Serum Zinc and Copper Level in CKD Patients
}

\author{
Shehab Elzain Hamad Balla ${ }^{1}$, Amar Mohamed Ismail ${ }^{2 *}$ \\ ${ }^{1}$ Department of Clinical Chemistry, Faculty of Medical Laboratory Science, University of AL-Neelain-Sudan. \\ ${ }^{2}$ Department of Biochemistry and Molecular Biology, Faculty of Science and Technology, University of AL-Neelain-Sudan.
}

\begin{tabular}{|c|c|}
\hline ARTICLE INFO & ABSTRACT \\
\hline Article history: & \multirow{6}{*}{$\begin{array}{l}\text { The aim of this study was to assess the effect of HD on zinc and copper level among CKD patients. A cross- } \\
\text { sectional study included } 40 \text { subjects ( } 15 \text { female and } 25 \text { male) from academic hospital aged (22-80 years old) were } \\
\text { included, timed pre and post-hemodialysis samples were collected. Serum zinc, copper, urea and creatinine were } \\
\text { measured by using atomic absorption spectroscopy } 210-\mathrm{VGP}^{\circledR} \text { and Mindray Bs-200 respectively, and BMI was } \\
\text { estimated. Paired t-test analyses showed significant decrease in mean copper, urea and creatinine with } p \text {-value } \\
(0.025,0.000 \text { and } 0.000) \text { respectively, while significant increase was observed in zinc level } p \text {-value } 0.035 \text {. } \\
\text { Person's correlation showed positive correlation between change in zinc level and reduction in urea, and no } \\
\text { correlation noted between change in serum copper level and reduction in urea and creatinine. In conclusion HD } \\
\text { decrease copper and increase zinc as both are antagonists, might play a vital role in pathogenesis of related } \\
\text { disorders in CKD Patients. }\end{array}$} \\
\hline Received on: 22/12/2015 & \\
\hline Revised on: 16/01/2016 & \\
\hline Accepted on: 08/02/2016 & \\
\hline Available online: $30 / 04 / 2016$ & \\
\hline $\begin{array}{l}\text { Key words: } \\
\text { Zinc, copper, CKD, dialysis } \\
\text { and hemodialysis. }\end{array}$ & \\
\hline
\end{tabular}

\section{INTRODUCTION}

End stage renal disease (ESRD) presents with water, electrolytes and menials disturbance, some of these disorders improved and others are continued or get worse with dialysis (Sud et al., 2014). Hemodialysis (HD) is the main treatment for patients with renal failure that are waiting for kidney transplantation or don't allow for kidney transplantation (Dakshinamurty et al., 2002), dialysis could lead to depletion of biologically essential substances if they are not included in the dialysate. For example, removal of water-soluble vitamins is well known and all dialysis patients are given supplements to replace dialysis losses (Wiesen et al., 2011). While data are available regarding vitamins in chronic kidney disease (CKD), little is known about the trace elements. Therefore the present study hypothized HD has an influence on trace elements and minerals thus patients with $\mathrm{CKD}$ at risk to develop a metabolic disorders due to deficiency and/or increase of these elements. CKD patients are at higher risk for zinc deficiency, with up to $78 \%$ of hemodialysis patients being deficient (Roozbeh et al., 2011),

\footnotetext{
* Corresponding Author

Amar Mohamed Ismail, Department of Biochemistry and Molecular Biology, Faculty of Science and Technology, University of AL-NeelainSudan. Email: amarqqqu[at]yahoo.com
}

which is required for numerous important biological activities in the body such as oxidative metabolism (Bozalioglu et al., 2005), and it is one of the main participants of immunological activities (Rink and Gabriel, 2001). Copper proteins have diverse roles in biological electron transport and oxygen transportation thus deficiency can cause anemia and neutropenia (Bonham et al., 2002). Non-protein bound copper ions are toxic by creating reactive oxygen species, which damage biological macromolecules (Brewer, 2010).

\section{MATERIALS AND METHODS}

In this cross-sectional study, forty subjects were enrolled from academic hospital on regular hemodialysis (two times a week) aged (22-80) years old. Random (5ml) vein-puncture blood specimen was withdrawn. Serum was obtained by centrifugation at $3000 \mathrm{rpm}$ for $10 \mathrm{~min}$ and stored at $-20{ }^{\circ} \mathrm{C}$ till used.

\section{Ethical considerations}

The study has been approved by the local ethics committee of Al-Neelain University. All participants in the study were given their written informed consent considering the aims of the study and sample and clinical information's were used anonymously. 


\section{Measurement of BMI}

Anthropometric data including weight and height were measured thus body mass index (BMI) was defined as weight $(\mathrm{Kg})$ divided by height squared $\left(\mathrm{m}^{2}\right)$.

\section{Estimation of zinc and copper}

Serum level of zinc and copper were measured using Atomic absorption spectrophotometer 210-VGP. Electron of the atom promoted to higher orbital's (excited state) for a short period of time by absorbing a defined quantity of energy. The amount of energy was specific to a particular electron transition in a particular element (Zinc or Copper).

The radiation measured by using detector and the absorbance was converted to analyte concentration (Zima et al., 1999). Brief according to the manufacture's protocol, serum zinc and copper were diluted 1:5 and 1:1 with deionized, then diluted serum aspirated and absorbance was measured at wave length $213.9 \mathrm{~nm}$ and $324.8 \mathrm{~nm}$ respectively.

\section{Estimation of urea}

Urea reacts with urease, ammonia product helps to turn $\mathrm{NADH}$ to NAD which catalysis of GLDH the decrease in absorbance is directly proportional to the concentration of urea in the sample. Absorbance was measured by using Mindray Bs-200 at $340 \mathrm{~nm}$.

\section{Estimation of creatinine}

Creatinine reacts with picric acid in alkaline medium to form an orange colored complex. The intensity of the color formed during fixed time reaction is directly proportional to the amount of creatinine in the sample. Absorbance was measured by using Mindray Bs-200 at $492 \mathrm{~nm}$.

\section{RESULTS AND DISCUSSION}

Mean zinc levels among pre and post hemodialysis samples

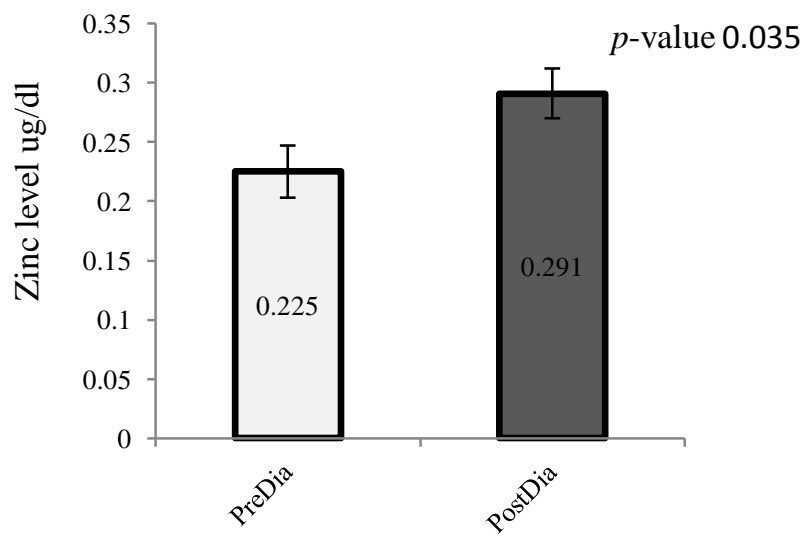

Fig. 3: Show mean concentration of zinc, results expressed as Mean \pm SD and significant difference considered as $p$-value $\leq 0.05$
Mean copper levels among pre and post hemodialysis samples

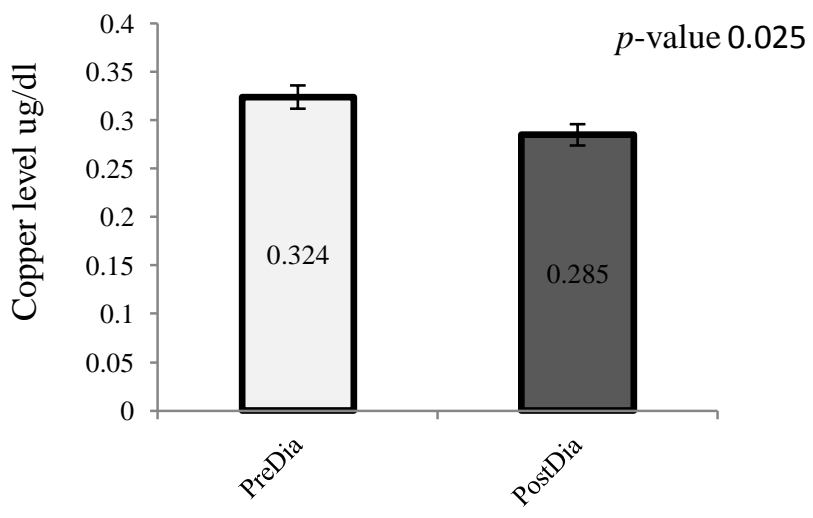

Fig. 3: Show mean concentration of copper, result expressed as Mean \pm SD and significant difference considered as $p$-value $\leq 0.05$.

Mean urea and creatinine level in pre and post hemodialysis samples

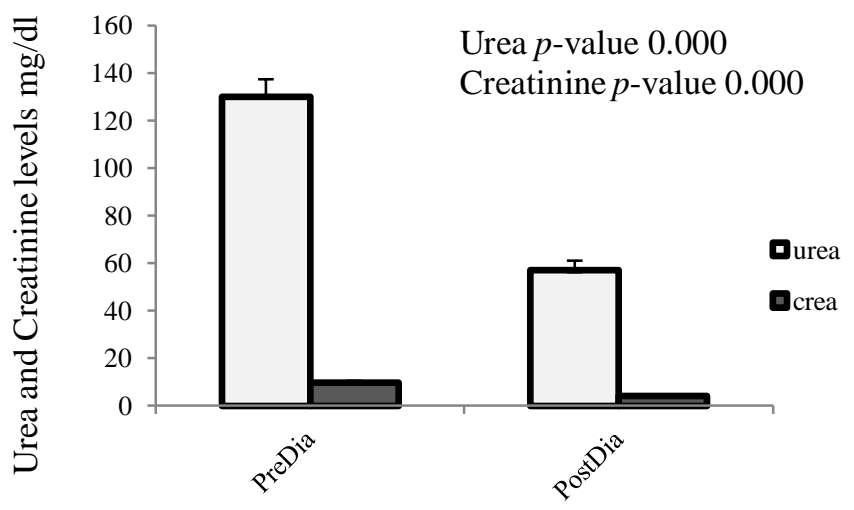

Fig. 3: Show mean concentration of urea and creatinine, result expressed as Mean \pm SD and significant difference considered as $p$-value $\leq 0.05$.

Change in study parameters (Zinc, copper, urea and creatinine)

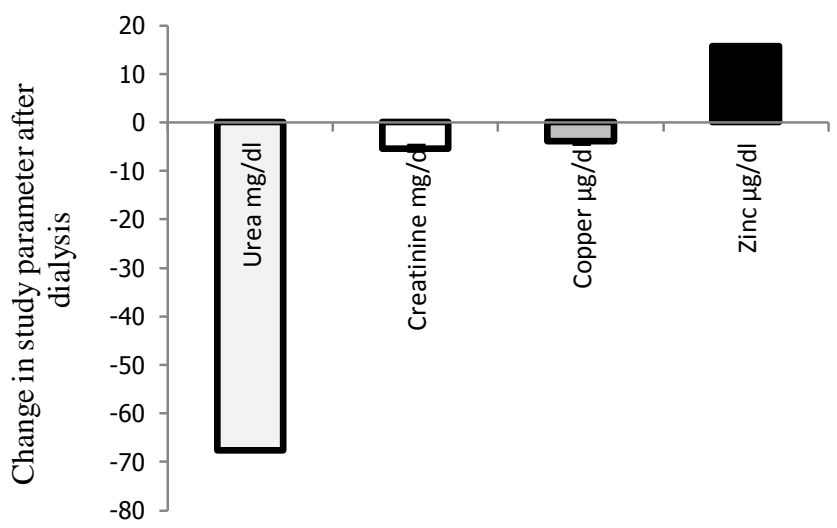

Fig. 4: Presenting mean concentrations of urea, creatinine, zinc and copper, results obtained by deduced post from pre-hemodialysis data, indicate increase in zinc and decreases in urea, creatinine and copper after hemodialysis. 
Independent t-test results of change in study parameters in gender

Table 1: Independent t-test analysis presenting the changes in mean concentration of study parameters (Zinc, Copper, Urea and Creatinine) among gender

\begin{tabular}{lccc}
\hline \multicolumn{1}{c}{ Variable } & $\begin{array}{c}\text { Male } \\
\text { Mean } \pm \text { SD }\end{array}$ & $\begin{array}{c}\text { Female } \\
\text { Mean } \pm \text { SD }\end{array}$ & p-value \\
\hline Zinc & $0.089 \pm 0.146$ & $0.160 \pm 0.196$ & 0.193 \\
Copper & $-0.032 \pm 0.066$ & $-0.049 \pm .067$ & 0.457 \\
Urea & $-65.7 \pm 42.2$ & $-70.8 \pm 30.6$ & 0.659 \\
Creatinine & $-5.72 \pm 3.29$ & $-4.72 \pm 2.51$ & 0.283 \\
\hline
\end{tabular}

Change obtained by deduced pre from post-hemodialysis results. Results expressed as means $\pm \mathrm{SD}$, significant difference consider as $\mathrm{p}$-value $\leq 0.05$.

\section{Correlation between study parameters and variables in Hemodialysis patients}

Table: 2 Person's correlation analysis show association between study parameters and variables in Hemodialysis patients.

\begin{tabular}{|c|c|c|c|c|}
\hline & BMI & AGE & GENDER & R. UREA \\
\hline BMI & & .181 & .000 & .145 \\
\hline$p$-value & & .131 & .499 & .187 \\
\hline AGE & .182 & & .193 & -.108 \\
\hline$p$-value & .131 & & .116 & .254 \\
\hline GEND & .000 & .193 & & -.066 \\
\hline$P$-value & .499 & .116 & & .342 \\
\hline R. UREA $R$-value & .145 & -.108 & -.066 & \\
\hline & .187 & .254 & .342 & \\
\hline R CREA $R$-value & .216 & -.063 & .163 & $.579^{* *}$ \\
\hline$p$-value & .090 & .351 & .157 & .000 \\
\hline C. ZINC $R$-value & .171 & -.072 & .210 & $.295^{*}$ \\
\hline$P$-value & .146 & .330 & .097 & .032 \\
\hline C. COPP $R$-value & .004 & -.164 & -.121 & -.033 \\
\hline$P$-value & .490 & .155 & .228 & .420 \\
\hline & & $\begin{array}{c}\text { R. } \\
\text { CREA }\end{array}$ & C. ZINC & C. COPP \\
\hline BMI & & .216 & .171 & .000 \\
\hline$p$-value & & .090 & .146 & .490 \\
\hline AGE & & -.063 & -.072 & -.164 \\
\hline$p$-value & & .351 & .330 & .155 \\
\hline GEND & & .163 & .210 & -.121 \\
\hline$P$-value & & .157 & .097 & .228 \\
\hline R. UREA $R$-value & & $.579^{* *}$ & $.295^{*}$ & -.033 \\
\hline$P$-value & & .000 & .032 & .420 \\
\hline R CREA $R$-value & & & .180 & -.030 \\
\hline$p$-value & & & .133 & .420 \\
\hline & & .180 & & -.182 \\
\hline$P$-value & & .133 & & .131 \\
\hline C. COPP $R$-value & & -.030 & -.182 & \\
\hline$P$-value & & .427 & .131 & \\
\hline
\end{tabular}

Hemodialysis treatment for patients with CKD may lead to increase or depletion of biologically function substances like trace elements thus hemodialysis patients are at theoretical risk for both deficiency and accumulation of these elements, depending on dialysis impact, composition of the source water used for hemodialysis, and residual kidney function (D'Haese et al., 1996; Zima et al., 1998). Thus could impact positive or negative on trace elements metabolism and functions. Accordingly the study aims to evaluate the impact of hemodialysis on serum zinc and copper and its correlation with study variables in patients with CKD. Previous study showed that, there was significant reduction of zinc in uremic patients compared to control group and serum zinc levels were increased after hemodialysis (Bozalioglu et al., 2005; Candan et al., 2002; Hosokowa et al., 1984). Present study has shown significant increase of serum zinc levels post-hemodialysis compared to pre-hemodialysis sample $p$-value 0.035 . The mechanism of elevated zinc after hemodialysis not yet understood, our suggestion could be related to increase transporter protein after hemodialysis, it is well known that zinc transported bound with prealbumin, albumin and transferrin, thus could protected against filtration during hemodialysis, this providing interesting observation that, beside elevated zinc levels after hemodialysis CKD patients have decrease zinc level. In fact that zinc deficiency in developing countries due to socioeconomic and malnutrition factors associated with delayed wound healing (Shrimpton et al., 2005; Prasad, 1988), and immune deficiency which might contribute to the excess risk of infection observed in hemodialysis patients (Collins et al 2005; Ishani et al., 2005; Rink and Gabriel, 2000).

The results of present study provide experimental evidence that, mean copper level was significantly decrease in post hemodialysis versus pre hemodialysis sample with $p$-value 0.025 . This finding was in agreement with previous report that copper level decrease in patients underwent hemodialysis and correlates positively with uremia (Kimmel, 2000). A deficiency of copper is known to affect the CNS, anemia and neutropenia (Douglas et al., 1978; Sen et al., 1991).

Person's correlation showed that, there was negative correlation between zinc and urea with p-value 0.032, suggest that contamination of the dialysis fluids and inability to remove these by dialysis lead to accumulation of the trace elements to toxic levels in the body (Sandstead, 1980). In ESRD patients different factors affect serum concentrations of trace elements like increased oral intake, failure of renal excretion, use of medications, quality of water used for dialysis and metabolic alterations associated with renal failure (Miura et al., 2002; Krachler and wiensherger, 2000; Miura et al., 1999). Serious, acute as well as chronic toxicities and deficiencies of trace elements have been reported (Miura et al., 1999; Covic and Gusbeth, 2009; D'Haese et al., 1996), which may have an impact on the severity of the disease and its complications.

\section{CONCLUSIONS}

The study concludes, HD decrease copper and increase zinc, as both are antagonists, might play a vital role in pathogenesis of related disorders in CKD patients. Regular screening is recommended to monitor neither increase nor decreases level, also to design supplementation treatment.

\section{ACKNOWLEDGEMENTS}

The authors acknowledge sincere thanks to Faculty of medical Laboratory Sciences, Al-Neelain University and Academic Hospital staff for the assistance in research work. 


\section{REFERENCES}

Bonham M, O'Connor JM, Hannigan BM, Strain JJ. The immune system as a physiological indicator of marginal copper status? $\mathrm{Br}$ J Nutr, 2002; 87:393-403

Bozalioglu S, Ozkan Y, Turan M, Simsek B. Prevalence of zinc deficiency and immune response in short-term hemodialysis. Journal of Trace Elements in Medicine and Biology, 2005; 18(3): 243-251.

Brewer GJ. Copper toxicity in the general population. Clin Neurophysiol, 2010; 121: 459-460.

Candan F, Gultekin F, Candan F. Effect of vitamin C and zinc on osmotic fragility and lipid peroxidation in zinc-deficient haemodialysis patients. Cell Biochem funct, 2002; 20: 95-102.

Collins AJ, Kasiske B, Herzog C, Chavers B, Foley R, Gilbertson D, Grimm R, Liu J, Louis T, Manning W, Matas A, McBean M, Murray A, St Peter W, Xue J, Fan Q, Guo H, Li S, Roberts T, Snyder J, Solid C, Wang C, Weinhandl E, Arko C, Chen SC, Dalleska F, Daniels F, Dunning S, Ebben J, Frazier E, Excerpts from the United States Renal Data System 2004 annual data report: atlas of end stage renal disease in the United States. Am J Kidney Dis, 2005; 45: 5-7.

Covic A, Gusbeth TP. Trace elements in endstage renal diseaseunfamiliar territory to be revealed. BMC Nephrology, 2009; 10: 12.

Dakshinamurty KV, PVLN Srinivasa Rao, KSS Saibaba, RB

Sheela, G Venkataramana, C Shyam and V Sreekrishna. Antioxidant status in patients on maintenance hemodialysis. Ind J Nephrol. 2002; 12:77-80.

D'Haese P C, Broe M E. Adequacy of dialysis: trace elements in dialysis fluids. Nephrol Dial Transplant, 1996; 11: 92-97.

Douglas E. Ryan, Jiri Holzbecher, and D. Craig Stuart. Trace elements in scalp-hair of persons with multiple sclerosis and of normal individuals. Clin. Chem, 1978; 24.

Hosokawa S, Imai T, Nishia T. Changes in copper and zinc in hemodialysis patients, EDTA - ERA Abstracts, 1984p 81.

Ishani A, Collins AJ, Herzog CA, Foley RN: Septicemia, access and cardiovascular disease in dialysis patients: the USRDS Wave 2 study. Kidney Int, 2005; 68:311-318.

Kimmel, P.L. Psychosocial factors in adult end-stage renal disease patients treated with hemodialysis: correlates and outcomes.Am. J. Kid. Dis, 2000; 35 (1): 132-140.

Krachler M, Wirnsberger G H. Long-term changes of plasma trace element concentrations in chronic hemodialysis patients. Blood Purif, 2000; 18: 138-143.

Miura Y, Nakai K, Sera K, Sato M. Trace elements in sera from patients with renal disease. Nucl. Inst. And Meth. in Phys. Res, 1999; 150: $18-21$.

Miura Y, Nakai K, Suwabe A, Sera K. Trace elements in renal disease and hemodialysis. Nuclear instruments and methods in physics research, 2002; 189: 443-449.

Prasad AS. Zinc in growth and development and spectrum of human zinc deficiency. J Am Coll Nutr, 1988; 7:377-384.
Rink L, Gabriel P. Extracellular and immunological actions of zinc. Biometals. 2001; 14 (3-4):367-383.

Rink L, Gabriel P: Zinc and the immune system. Proc Nutr Soc 2000; 59:541-552.

Roozbeh J, Sharifian M, Sagheb MM, Shabani S, Hamidian Jahromi A, Afshariani R, Pakfetrat M, Salehi O. Comment on: does zinc supplementation affect inflammatory markers in hemodialysis patients? Am J Clin Nutr, 2011; 67:965-971

Sandstead H. Harold. Trace elements in uremia and hemodialysis. American journal of clinical nutrition, 1980; 33: pp. 15011508 .

Sen S, Bor N, Colakoglu M, Gultekin A. Clearance of zinc and copper during hemodialysis. Journal of Islamic academy of sciences, 1991; 4: 3, 265-267.

Shankar AH, Prasad AS: Zinc and immune function: the biological basis of altered resistance to infection. Am J Clin Nutr, 1998; 68:447-463.

Shrimpton R, Gross R, Hill I, Young M: Zinc deficiency: what are the most appropriate interventions? BMJ, 2005; 330:347-349.

Sud M, Tangri N, Pintilie M, Levey AS, Naimark DM. ESRD and Death after Heart Failure in CKD. Journal of the American Society of Nephrology, 2014; 253.

Wiesen P, Van Overmeire L, Delanaye P, Dubois B, Preiser JC Nutrition disorders during acute renal failure and renal replacement therapy. J Parenter Enteral Nutr, 2011; 35:217-222

Zima T, Mestek O, Nemecek K, Bartova V, Fialova J, Tesar V, Suchanek M: Trace elements in hemodialysis and continuous ambulatory peritoneal dialysis patients. Blood Purif, 1998; 16:253-260.

Zima T, Tesar V, Mestek O, Nemecek K: Trace elements in endstage renal disease. Clinical implication of trace elements. Blood Purif, 1999; 17:187

\section{How to cite this article:}

Amar Mohamed Ismail, Shehab Elzain Balla. Impact of Hemodialysis on Serum Zinc and Copper Level In Ckd Patients. J App Pharm Sci, 2016; 6 (04): 165-168. 